\title{
Therapeutic and Ameliorative Effects of Active Compounds of Combretum molle in the Treatment and Relief from Wounds in a Diabetes Mellitus Experimental Model
}

\author{
Reham Z. Hamza ${ }^{1, *}$, , Shaden E. Al-Motaani ${ }^{2}$ and Tarek Al-Talhi ${ }^{3}$ \\ 1 Biology Department, College of Sciences, Taif University, Taif-P.O. Box 11099, Taif 21944, Saudi Arabia \\ 2 General Department of Education, Taif 21944, Saudi Arabia; fawzeh_a@yahoo.com \\ 3 Chemistry Department, College of Sciences, Taif University, Taif-P.O. Box 11099, Taif 21944, Saudi Arabia; \\ t_talhi@yahoo.com \\ * Correspondence: Reham.z@tu.edu.sa or dr_reham_z@yahoo.com
}

Citation: Hamza, R.Z.; Al-Motaani, S.E.; Al-Talhi, T. Therapeutic and Ameliorative Effects of Active Compounds of Combretum Molle in the Treatment and Relief from Wounds in a Diabetes Mellitus Experimental Model. Coatings 2021, 11, 324. https://doi.org/10.3390/ coatings11030324

Academic Editor: El-Sayed Abd El-Aziz

Received: 10 February 2021 Accepted: 5 March 2021 Published: 11 March 2021 Retracted: 16 August 2022

Publisher's Note: MDPI stays neutral with regard to jurisdictional claims in published maps and institutional affiliations.

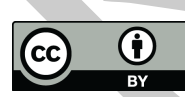

Copyright: (c) 2021 by the authors. Licensee MDPI, Basel, Switzerland. This article is an open access article distributed under the terms and conditions of the Creative Commons Attribution (CC BY) license (https:// creativecommons.org/licenses/by/ $4.0 /)$.

\begin{abstract}
Foot ulcers are one of the leading causes of severe and high mortality in diabetics. It is known that wound healing in diabetics is a very complicated process due to the direct severe effect of diabetes mellitus on blood vessels, causing difficulty in wound healing. Many methods of treatment have recently been employed for novel dressings for the promotion of tissue regeneration and rapid wound closure. Combretum molle is composed of chemical compounds, such as lignin, gallic acid, and ellagic acid. Twenty male rats that were 4 months of age were divided into a I-a diabetic foot ulcer group as the control group and a II-a diabetic group (wound + Combretum molle). This study investigated the antioxidant and excellent healing effects of the extract of Combretum molle in repairing skin damaged by diabetes. This was confirmed by elevated antioxidant enzymes in the animals' tissues in diabetic rats treated with this extract. The recovery of the alterations in the skin layers led to great improvements, which proved the Combretum molle's promising capacity for wound healing in diabetics with wounds that mimic diabetic foot ulcers. This treatment can be considered a promising opportunity for patients with severe foot ulcers and may open the door to more discoveries about this plant's medical capabilities.
\end{abstract}

Keywords: diabetes mellitus; diabetic wounds; Combretum molle; wound healing

\section{Introduction}

Combretum molle is a herbal plant in the family of Combretaceae, which includes about 600 species and about 20 genera [1]. This plant is usually used for the treatment of stomach pain, abdominal disorders, and severe dysentery [2]. Additionally, the roots of this plant have different uses against fever, snake bite, and general swellings [3].

The bark and roots of this plant were tested in vitro for the treatment of different bacterial strains [4]. Additionally, seeds of the plant were tested against fungi and bacteria [5], and the leaves were tested against helminths [6].

Additionally, a lot of Combretum molle species were reported to have antiplasmodial activity in vitro chloroquine-sensitivity against Plasmodium falciparum strains [7]. Traditional medicinal plants are used for the treatment of malaria and other diseases, while the seeds of Combretum molle are widely used by local people for the treatment of various diseases; their effects combine with a Xylopia aethiopica extract for wound healing, as Mensah et al. [8] reported that ethnomedicinal wound care using Combretum molle (stem bark) and Xylopia aethiopica (fruit) coextracts has implications for healthy wound healing and can be brought forward into clinical practice and public health. Therefore, the objective of the current study was to investigate the in vivo effect of the Combretum molle plant extract on alleviating wounds and burns and mitigating their effects on the skin, improving the oxidant status, and some biochemical parameters. Foot ulcers are one of the major 
causes of the severe mortality seen in diabetics, where the economic burden is felt more in developing countries [9]. People with diabetes often also have hyperglycemia, where hyperglycemia usually leads to various complications. Diabetic foot is one of the serious chronic complications of diabetes. Diabetic foot wounds are difficult to heal [10].

Reports demonstrate that there were 285 million diabetics in 2010, and this is likely to increase to more than 360 million by 2030. The probability of diabetics developing foot ulcers is about 15-25\% during their life, and the risk of lower amputations is about 17-40 times higher among diabetics than among their healthy counterparts [11].

Diabetes is increased among obese individuals and more in male patients. About one-third of elderly diabetics contract foot ulcers because of chronic neuropathy, which is a wound on the foot that arises in the two types of diabetes mellitus [12].

Delayed wound healing (especially in a diabetic foot ulcer) is considered to be one of the major complications of diabetes mellitus [13], which is commonly present in uncontrolled diabetic patient cases. Diabetic ulcers have shown an increasing trend over recent decades. In total, it is estimated that $15 \%$ of patients with diabetes suffer from ulcers [14].

Diabetic ulcers are reported to be a major source of severe morbidity and the main cause for hospitalization in diabetics [15].

Additionally, the tannin, seeds, leaf extracts, and stem bark of Combretum molle plant were revealed to have in vitro activity against Plasmodium falciparum [16].

Almost every part of the plant Combretum molle has been used in traditional medicine for the treatment of various diseases [17]. Specifically, the seeds of this plant are widely used to fight against infection, gangrene, amputation, and death in some neglected cases. Moreover, diabetic ulcers are responsible for physical distress, as well as productivity and financial losses, which lead to a severe economic burden [18].

Several researchers have carried out experiments on numerous dressing materials. Reports on other treatment modalities have also been extensively studied. Hyperbaric oxygen therapy, electrical stimulation, and bioengineered skin are some of the other proven adjunct therapies in the treatment of diabetic foot ulcers [19].

The smart dressings and their components have been reviewed recently. The contribution of natural and synthetic materials and composite forms was previously reported by Pazyar et al. [20].

Vertebrate models are essential for burn research since new therapeutic modalities must first be investigated at the experimental level before clinical use. Many animals have been used in experimental burn models: dogs, sheep, rabbits, guinea pigs, hamsters, pigs, and primates. By far, rats and mice have been the most frequently used species in burn models [21].

The novelty of this study is in investigating the wound-healing effect of Combretum molle leaf extract in diabetics, which is of major clinical importance. Therefore, the aim of the current study was to assess the healing and antioxidant effects of Combretum molle extract against wounds and deep burns, especially in diabetic foot in diabetics.

\section{Materials and Methods}

\subsection{Combretum molle Material Preparation}

The Combretum molle was collected from a mountainous area in the village of Rubua AlAin in the Adam Governorate of the Makkah Region. The plant was identified, deposited, and analyzed at the Pharmacognosy Department at the Faculty of Pharmacy, Sattam University, Saudi Arabia, and HPLC-UV analysis was performed at the College of Science, Taif University, Taif, Saudi Arabia. Leaves of the plant were collected, dried, powdered, and kept in a closed bottle until extraction. The powdered leaves (100 g) were extracted by maceration in $300 \mathrm{~mL}$ of $80 \%$ methanol for a consecutive $72 \mathrm{~h}$ [22]. The mixture was filtered by using No. 1 Whatman filter paper. The residue was remacerated for another $72 \mathrm{~h}$ twice and then was filtered. The combined filtrate was then dried using a rotary evaporator at a temperature of $40^{\circ} \mathrm{C}$ and a speed of $45 \mathrm{rpm}$. After drying in a water bath, the dried extract was kept at $-20^{\circ} \mathrm{C}$ in a deep freezer until being used. 


\subsection{Chemical Composition of the Combretum molle Plant Extract}

The plant extract was chemically analyzed in the Faculty of Pharmacy, Satttam University, AlKharg, Saudi Arabia. Some experiments were carried out to identify the components of the plant.

- Alkaloids:

Each C. molle extract was mixed with 1\% hydrochloric acid and treated with Mayer's, Wagner's, and Dragendorff's reagents. Creamy white (with Mayer), reddish-brown (with Wagner), or orange (with Dragendorff) precipitates indicated the presence of alkaloids.

- Saponins:

Saponins were detected via the addition of distilled $\mathrm{H}_{2} \mathrm{O}$ to the $\mathrm{C}$. molle extract. After heating, the filtrates were shaken. The formation of a froth confirmed saponins' presence.

- Steroids:

The C. molle extract was dissolved in $2 \mathrm{~mL}$ of chloroform. Concentrated sulfuric acid was added to the extract. A red color was produced, which indicated the steroids' presence.

- Flavonoids:

Each C. molle extract was dissolved in sodium hydroxide. A yellow solution that turned colorless with the addition of hydrochloric acid indicated the presence of flavonoids.

- Cardiac glycosides:

Each C. molle extract was dissolved in glacial acetic acid with $\mathrm{FeCl}_{3}$. A brown ring indicated the presence of cardiac glycosides.

- Anthraquinones:

The C. molle extract was shaken with benzene. The mixture was filtered and $10 \% \mathrm{NH}_{3}$ solution was added to the extract. The presence of a pink or violet color indicated the presence of anthraquinones.

- Tannins:

Each C. molle extract was mixed with $\mathrm{H}_{2} \mathrm{O}$. A green precipitate or blue-black precipitates with the addition of $\mathrm{FeCl}_{3}$ to the extract was an indication of the presence of tannins.

\subsection{HPLC-UV of the Plant Extract Combretum molle}

UHPLC (ultra-high-performance liquid chromatography) qualitative analyses for the Combretum molle extract were performed according to Fyhrquist et al. [3]. Elution was performed by using (A) $0.1 \%$ formic acid and (B) $100 \%$ acetonitrile. The flow rate was $1 \mathrm{~mL} / \mathrm{min}$. A UV chromatogram was constructed between 246.22 to $301.07 \mathrm{~nm}$ and compared to reference compounds in the system library.

\subsection{Experimental Animals}

Twenty adult male rats with weights of 150-180 g were preserved in hygienic metal cages. The experimental protocols were approved by the Animal Ethical Committee of Taif University under approval number 42-0044 while following the health guidelines for animal use at the U.S. institutes.

\subsubsection{Experimental Animal Design}

After a period of acclimation with healthy diets and water ad libitum, the male rats were randomly divided into two main diabetic groups (10 rats/group; Figure 1) that represented diabetic foot ulcers as follows:

1. Diabetic deep wound-positive control group.

2. Diabetic deep wound-Combretum molle extract group. 


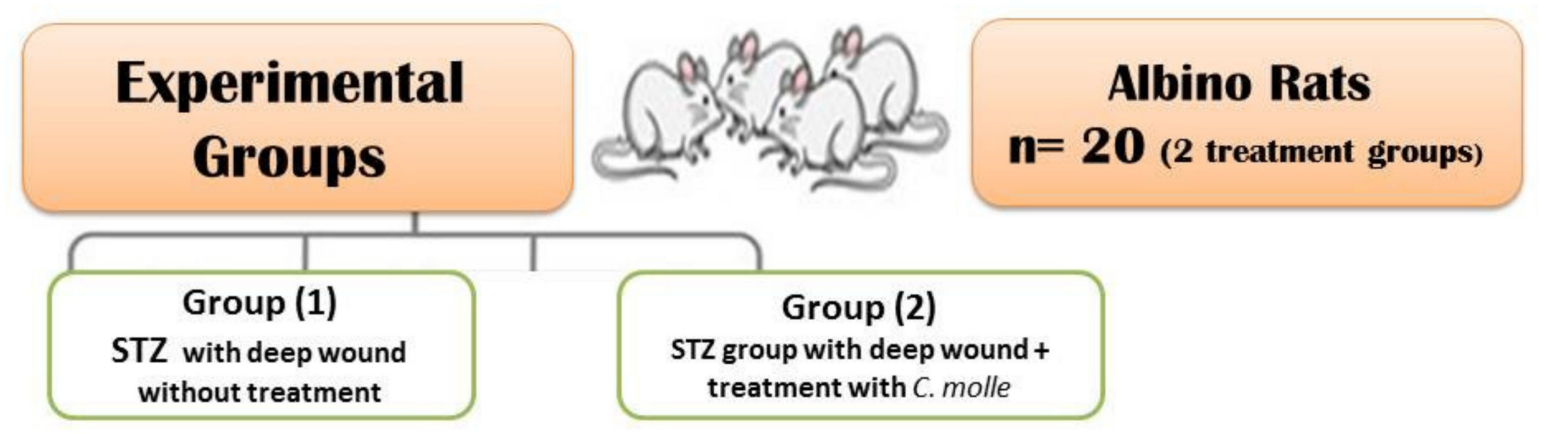

Injected with STZ: Streptozotocin I.P in the treated groups

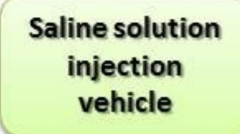

STZ

$50 \mathrm{mg} / \mathrm{kg}$

Combretum molle

Powdered leaves $100 \mathrm{~g}$ was extracted by

maceration in $300 \mathrm{~mL} 80 \%$ methanol.

After the end of the experiment, These biochemical analysis were performed

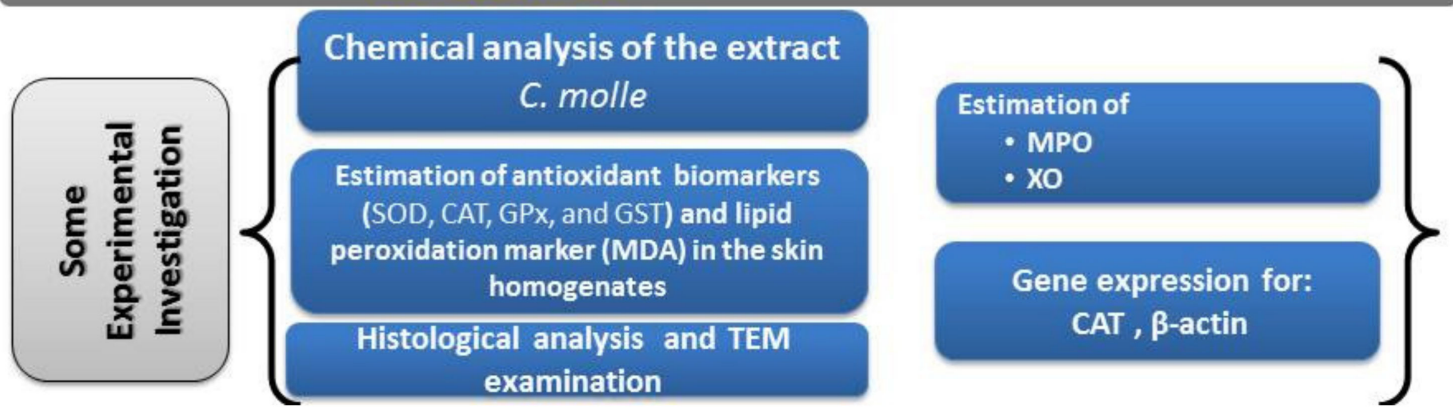

Figure 1. Experimental design.

2.4.2. Diabetes Mellitus Experimental Model

Streptozotocin (STZ) was dissolved in a freshly prepared acidic buffer saline solution. Diabetes mellitus was induced by STZ injection (i.P) at a dose of (50 mg/ kg), as reported by El-Megharbel et al. [23]. Treatments were continued for 4 successive weeks and the experiment was started $72 \mathrm{~h}$ after the i.P injection of STZ. The diabetic case was considered by measuring the blood glucose level using glucose monitor 3 days after the STZ injection. Blood glucose levels that were higher than $280 \mathrm{mg} / \mathrm{dL}$ were considered to signify diabetes.

The first group (Group A) was considered as a positive control group, where a wound was made using a sterilized scalp after light anesthesia to mimic a deep wound to a diabetic foot.

Group B (the STZ group) involved the incidence of the deep wound, as described previously, which was then wiped over using the prepared extract of Combretum molle twice daily for 4 weeks.

\subsection{Blood Sample Collection}

Blood samples were taken from the eye plexus of rats using Heparinized capillary tubes with anesthesia via ether. Samples of the blood were centrifuged at $4000 \mathrm{rpm}$ for about 15 min to allow for biochemical analyses. The rats were sacrificed and the skin tissues were preserved at $-20{ }^{\circ} \mathrm{C}$ for further biochemical analyses.

\subsection{Tissue Homogenate Preparation for the Measurement of Oxidative Stress Markers}

Another portion of the skin tissues was used for the estimation of antioxidant parameters. They were washed with normal physiological saline $(0.9 \%)$ and then were blotted on the filter paper. Dermal tissues were then perfused with a slightly basic buffer solution. 
Then, the skin tissue homogenates were homogenized in $5 \mathrm{~mL} / \mathrm{g}$ of buffer and centrifuged at $5000 \mathrm{rpm}$ for $0.5 \mathrm{~h}$. Then, the resulted homogenate supernatant was used.

\subsection{Determination of Markers of Oxidative Stress}

Skin tissue homogenates were used for the estimation of myloperoxidase (MPO) and xanthine oxidase (XO) enzymes. MPO is present mostly in the neutrophils. MPO Kit number ab111749 provided a method for studying the MPO activities. XO was assayed at $650 \mathrm{~nm}$, as described by Litwack et al. [24]. Reduced glutathione (GRx) was assessed according to Sedlak and Lindsay [25]. Skin lipid peroxides were expressed as malondialdehyde (MDA) according to Ohkawa et al. [26]. Catalase (CAT) was determined according to Beers and Sizer [27]. Glutathione-S-transferase (GST) was estimated according to Couri and Abdel-Rahman [28], and GPx was estimated according to Glodberg and Spooner [29].

\subsection{Estimation of Inflammation Biomarkers}

C-reactive protein (CRP) was determined according to Wener et al. [30] by using an ELISA Assay Kit (SEA821).

\subsection{Mitochondrial Function}

2.9.1. Evaluation of Succinate Dehydrogenase (SDH, Complex II) Activity

Metabolic-viability-based assays using tetrazolium salts were used for the mitochondrial metabolic rate measurements. The SDH activity was estimated at an absorbance of $570 \mathrm{~nm}$ (Tecan, Rainbow Thermo, Austria) [30].

\subsubsection{Mitochondrial ROS Assay}

ROS generation was evaluated by using a dichlorodihydrofluorescein diacetate (DCFHDA probe). Mitochondrial suspensions from the skin tissues obtained with the DCFHDA were incubated at $10 \mu \mathrm{M}$ at $30^{\circ} \mathrm{C}$ for about $30 \mathrm{~min}$. The fluorescence intensity of DCF was measured using a Shimadzu RF-5000U spectrophotometer $(\lambda \mathrm{Ex}=488 \mathrm{~nm}$ and $\lambda$ $\mathrm{Em}=527 \mathrm{~nm}$, Kyoto, Japan). An increase in fluorescence intensity indicated an increase in the generation of ROS [31].

\subsubsection{Mitochondria Membrane Potential (MMP, $\Delta \Psi \mathrm{m}$ ) Assay}

The mitochondria of the dermal tissues were isolated from the treated groups. The mitochondrial ROS generation was evaluated by using rhodamine 123 (Rh123) at $10 \mu \mathrm{M}$ at $30{ }^{\circ} \mathrm{C}$ for $30 \mathrm{~min}$. The collapse in MMP was evaluated using a Shimadzu RF-5000 U fluorescence spectrophotometer $(\lambda E x=490 \mathrm{~nm}$ and $\lambda E m=535 \mathrm{~nm})$. An increase in intensity indicated an increase in the MMP collapse [32].

\subsubsection{Mitochondrial Membrane Potential via Fluorescent Detection}

Skin tissues were washed and rinsed with ice. They were blotted on a filter paper and weighed on a digital balance. A fluorescent kit was measured using a Fluoroskan Ascent Fluorometer microplate reader (Thermo Fisher Scientific, Tecan, Rainbow, Austria).

\subsubsection{Evaluation of Swelling of the Mitochondria}

The swelling of the mitochondria was measured using an ELISA reader (Rainbow Thermo, Thermo Fisher Scientific, Waltham, MA, USA) at $540 \mathrm{~nm}$. A decrease in absorbance indicated an elevation in mitochondrial swelling [32].

\subsubsection{Cytochrome C Oxidase Release Assay}

Evaluation of cytochrome $c$ release was measured using a Quantikine Immunoassay kit for Rats (Minneapolis, MN, USA) [33]. 


\subsubsection{ATP Content Assay}

The ATP content was detected by using the luciferase enzyme. The intensity was measured by using a Sirius tube luminometer (Berthold Detection System, Bad Wildbad, Germany). The ATP content was expressed as nanomoles per milligram of protein [34,35].

\subsection{Transmission Electron Microscopic Study (TEM)}

A portion of the skin tissue was fixed and kept in $2.5 \%$ glutaraldehyde. The specimens were then carried on copper grids for further examination [36].

\subsection{Histological Analysis of Skin Tissues}

The skin tissues were rinsed and fixed in 10\% neutral-buffered formalin. After the fixation, the samples were embedded in paraffin; then, thin sections were cut and stained with hematoxylin and eosin (H\&E) and examined using a light microscope.

\subsection{RNA Isolation and Quantitative Reverse Transcription Polymerase Chain Reaction}

Gene expressions of CAT were examined using polymerase chain reaction (PCR). Total RNA was isolated by using a TRIzol reagent. The data were analyzed using the ${ }^{-}{ }^{\Lambda \Lambda} \mathrm{Ct}$ method and the obtained values were compared to those of $\beta$-actin.

\subsection{Statistical Analysis}

Statistical analysis was done using SPSS software version 27 (IBM, 2020). Graphical and tabular presentations were done. The data were summarized as the mean and standard deviation. The Shapiro-Wilk test was used to determine the distribution characteristics of variables and variance homogeneity. Student's $t$-test was used to analyze the data. A $p$-value of $<0.05$ was accepted as statistically significant [37].

\subsection{Sample Size}

We assumed that CAT levels in the diabetic group with a deep wound (positive control) group versus the diabetic group with a deep wound that was treated with the $C$. molle extract were $5.5 \pm 0.85 \mathrm{U} / \mathrm{g}$ versus $4.8 \pm 0.9 \mathrm{U} / \mathrm{g}$. At a power of $80 \%$ and a confidence level of $95 \%$, the required sample size was 20 (10 in every group). This sample was calculated using the OPEN EPI software package [37].

\section{Results}

\subsection{Chemical Composition of the Novel Ointment}

The current results showed that the used extract of Combretum molle showed the presence of a lot of active compounds, where the leaf extract contained the following compounds: alkaloids, carbohydrates, saponin glycosides, anthraquinone glycosides, flavonoids, unsaturated sterols and/or triterpenes, phenols (tannins), proteins, and lignin, with only the absence of cardiac glycosides. All the present compounds contributed to the healing and mitigating effect of the skin due to the presence of a lot of important compounds, especially lignin, saponin glycosides, and anthraquinone glycosides. The antioxidant effect of the extract may have been due to the presence of flavonoids and phenols (Table 1).

The results indicated the chemical compounds of the $C$. molle extract as identified using UHPLC, where the chemical composition was rich in gallic acid and its derivatives, gallic acid, gallic acid derivative, protocatechuic acid, O-hydroxycinnamic-acid-like substance, ellagitannin, three unknown ellagitannins, corilagin derivative, punicacortein D, sanguiin H-4, gallotannin, B-Punicalagin, an epigallocatechin-like substance, ellagic acid derivative, lignan, and a procyanidin-B-3-like substance, which almost completely consisted of polyphenolic and flavonoid compounds, as shown in (Figure 2 and Table 2). 
Table 1. Chemical components of the Combretum molle plant's dried leaves.

\begin{tabular}{|c|c|c|c|}
\hline No. & Chemical Group & Reagent (Test) Used to Detect & Results of Screening $(+$ or - ) of the Leaf Powder \\
\hline 1 & Cardiac glycosides & Keller Kelliani's test & - \\
\hline \multirow{3}{*}{2} & \multirow{3}{*}{ Alkaloids } & Mayer's test & + \\
\hline & & Wagner's test & + \\
\hline & & Dragendroff's test & + \\
\hline 3 & Carbohydrates & Molisch's test & + \\
\hline \multirow{2}{*}{4} & \multirow{2}{*}{ Saponin glycosides } & Froth test & + \\
\hline & & Foam test & + \\
\hline 5 & Anthraquinone glycosides & Modified Borntrager's test & + \\
\hline \multirow{2}{*}{6} & \multirow{2}{*}{ Flavonoids } & Lead acetate test & + \\
\hline & & Alkaline reagent test & + \\
\hline \multirow{2}{*}{7} & \multirow{2}{*}{$\begin{array}{l}\text { Unsaturated sterols } \\
\text { and/or triterpenes }\end{array}$} & Libermann Burchard's test & + \\
\hline & & Salkowski's test & + \\
\hline 8 & Phenols (tannins) & Ferric chloride test & + \\
\hline 9 & $\begin{array}{l}\text { Proteins and } \\
\text { amino acids }\end{array}$ & Ninhydrin test & + \\
\hline 10 & Lignin & Phloroglucinol & + \\
\hline
\end{tabular}

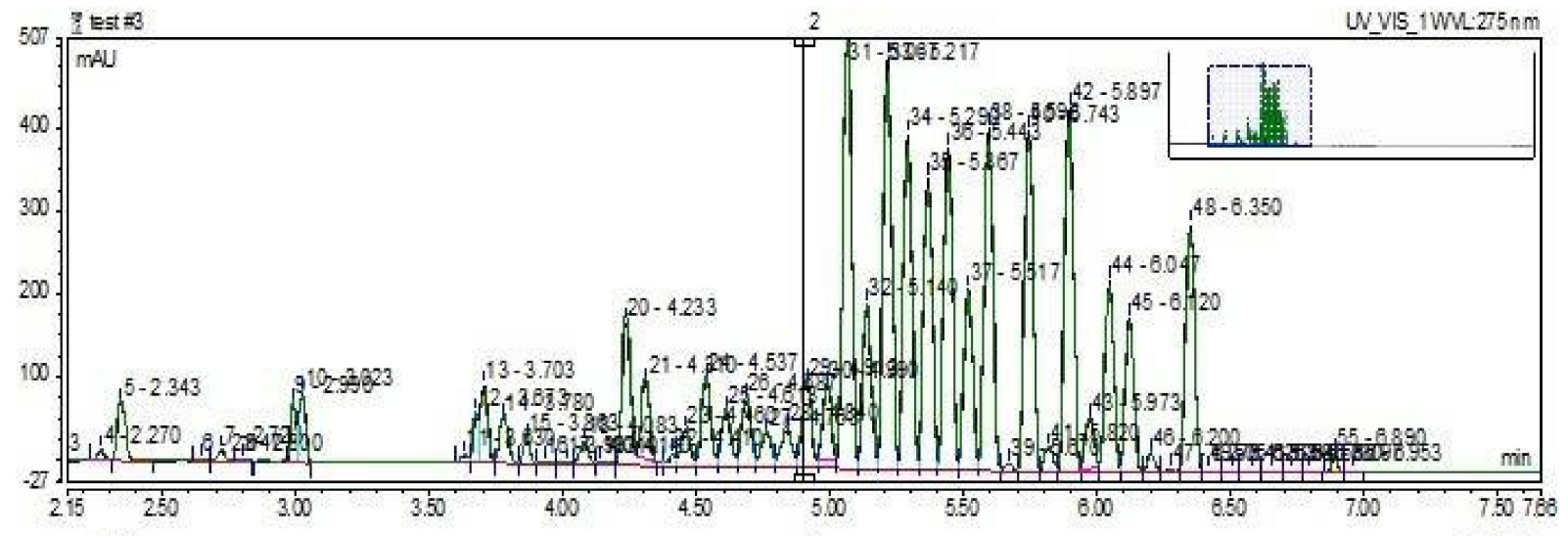

test $: 3$

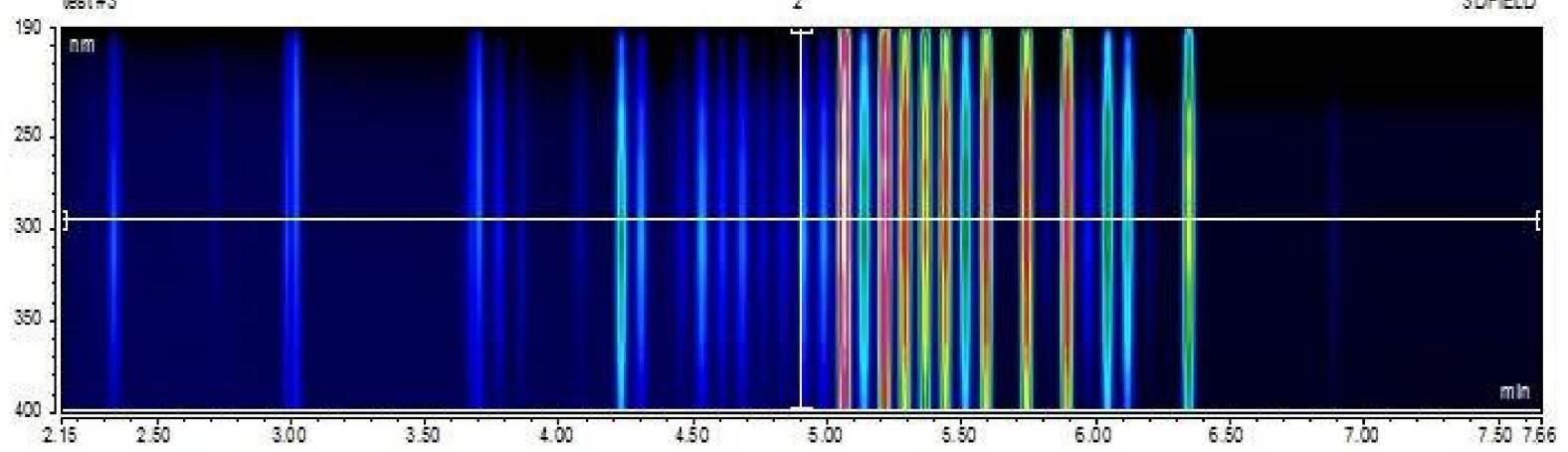

Figure 2. UHPLC and UV charts of the C. molle extract. 
Table 2. Polyphenolic profile of the methanolic extract of Combretum molle for dried leaves of the plant. Data were recorded using UHPLC flight mass spectrometry.

\begin{tabular}{cccc}
\hline No. & Compounds & Molecular Composition & Rt-UHPLC (min) \\
\hline 1 & Gallic acid & $\mathrm{C}_{7} \mathrm{H}_{6} \mathrm{O}_{5}$ & 1.370 \\
2 & Gallic acid derivative & - & 2.343 \\
3 & Protocatechuic acid & $\mathrm{C}_{7} \mathrm{H}_{6} \mathrm{O}_{4}$ & 2.722 \\
4 & - & 2.990 \\
5 & O-hydroxycinnamic-acid-like substance & $\mathrm{C}_{44} \mathrm{H}_{32} \mathrm{O}_{27}$ & 3.023 \\
6 & Ellagitannin & - & 3.630 \\
7 & Unknown ellagitannin & $\mathrm{C}_{27} \mathrm{H}_{22} \mathrm{O}_{18}$ & 3.703 \\
8 & Corilagin derivative & $\mathrm{C}_{48} \mathrm{H}_{28} \mathrm{O}_{30}$ & 3.863 \\
9 & Punicacortein D & - & 4.083 \\
10 & Unknown ellagitannin & - & 4.233 \\
11 & Unknown ellagitannin & $\mathrm{C}_{27} \mathrm{H}_{22} \mathrm{O}_{18}$ & 4.462 \\
13 & Sanguiin H-4 & $\mathrm{C}_{76} \mathrm{H}_{52} \mathrm{O}_{46}$ & 5.030 \\
14 & Gallotannin & $\mathrm{C}_{48} \mathrm{H}_{28} \mathrm{O}_{30}$ & 5.299 \\
15 & B-punicalagin & - & 5.367 \\
16 & An epigallocatechin-like substance & - & 5.517 \\
17 & Ellagic acid derivative & $\mathrm{C}_{25} \mathrm{H}_{30} \mathrm{O}_{8}$ & - \\
20 & Lignan & - & 5.743 \\
\end{tabular}

\subsection{Biological Results}

3.2.1. Morphological Aspects of the Wound Healing in the Different Treated Groups

It is clear from Figure 3 that the diabetic group with the incidence of a wound that was treated with the extract of Combretum molle showed a great improvement in the wound, with the disappearance of the redness and edema from the third week to the fourth week and the appearance of a normal foot without ulcers. It is apparent from Figure 3 that the diabetic deep wound group that was treated with the extract of Combretum molle showed high levels of skin regeneration with an excellent ability to heal the wounds, which is especially important given the diabetic side effects caused by diabetic foot ulcers. This shows the great success of the extract of Combretum molle in successfully healing diabetic wounds.

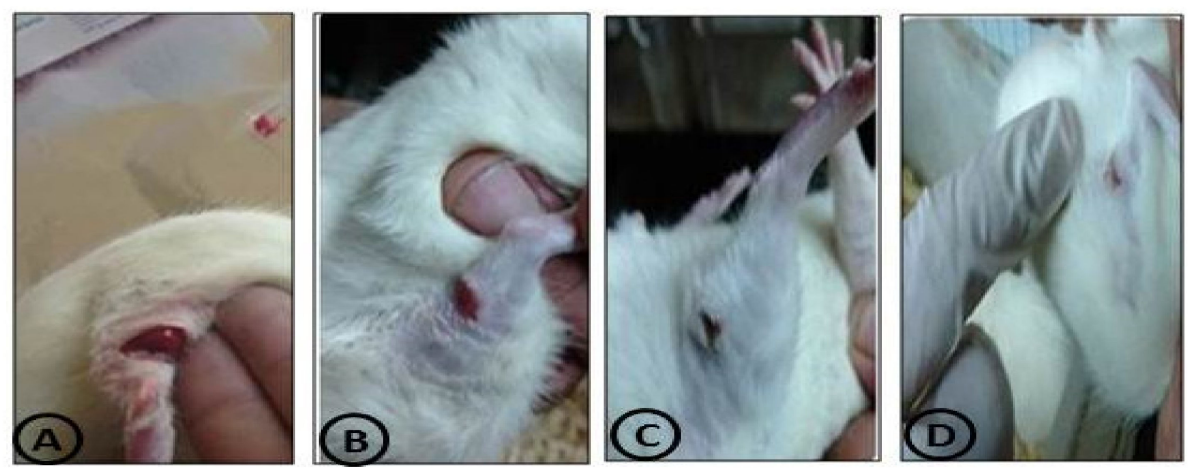

Figure 3. Variations in live sections of the wound healing model and the rats treated with the C. molle extract: (A) diabetic group with a deep wound, (B) diabetic group with a deep wound after 1 week of treatment with C. molle, $(\mathrm{C})$ diabetic group with a deep wound after 2 weeks of treatment with $C$. molle, and (D) diabetic group with a deep wound after 3 weeks of treatment with C. molle.

\subsubsection{Oxidative Stress Biomarkers}

Table 3 shows that the STZ diabetic group with a deep wound (untreated group) displayed a significant decrease in CAT, SOD, GRx, and GST enzymes, while inducing a significant elevation in MDA. Furthermore, this group displayed a significant elevation in myloperoxidase and xanthine oxidase levels, as shown in Table 4. The treatment of 
diabetic rats with a deep wound with the extract of Combretum molle induced significant elevations in CAT, SOD, GRx, and GST levels as compared to the diabetic control group, while eliciting significant declines in the MPO, XO, and MDA levels as compared to the diabetic with deep wounds control group.

Table 3. Changes in the oxidative/antioxidant parameters of the antioxidant enzymes of the control diabetic rats with deep wounds and the rats treated with the Combretum molle extract.

\begin{tabular}{ccccc}
\hline $\begin{array}{c}\text { Oxidative/Antioxidant } \\
\text { Parameters }\end{array}$ & $\begin{array}{c}\text { Control Group } \\
(\boldsymbol{n}=\mathbf{1 0})\end{array}$ & $\begin{array}{c}\text { Treated Group } \\
(\boldsymbol{n}=\mathbf{1 0})\end{array}$ & $\boldsymbol{t}$ & $\boldsymbol{p}$-Value \\
\hline CAT (U/g) & $0.74 \pm 0.2$ & $3.2 \pm 0.8$ & 9.4 & $<0.001^{*}$ \\
SOD (U/g) & $8.1 \pm 0.4$ & $20.9 \pm 4.2$ & 9.6 & $<0.001 *$ \\
MDA (U/g) & $69.8 \pm 4.1$ & $9.3 \pm 0.2$ & 46.6 & $<0.001^{*}$ \\
GPX (U/g) & $4.1 \pm 0.1$ & $14.2 \pm 2.4$ & 13.3 & $<0.001 *$ \\
GST (U/g) & $4.2 \pm 0.4$ & $12.2 \pm 2.8$ & 8.9 & $<0.001^{*}$ \\
\hline
\end{tabular}

$t$ : Student's $t$-test. Results are presented as mean \pm SD. Means within the same column in each category (mean \pm SE). SOD: superoxide dismutase; MDA: malondialdhyde; CAT: catalase; GRx: glutathione reductase; GST: glutathione-S-transferase. * represent $p$-value, where $p$-value $<0.001$ was considered highly significant.

Table 4. Changes in MPO and XO of the control diabetic rats with deep wounds and the rats treated with the Combretum molle extract.

\begin{tabular}{ccccc}
\hline $\begin{array}{c}\text { Oxidative/Antioxidant } \\
\text { Parameters }\end{array}$ & $\begin{array}{c}\text { Control Group } \\
(\boldsymbol{n}=\mathbf{1 0})\end{array}$ & $\begin{array}{c}\text { Treated Group } \\
(\boldsymbol{n}=\mathbf{1 0})\end{array}$ & $\boldsymbol{t}$ & $\boldsymbol{p}$-Value \\
\hline $\mathrm{MPO}(\mathrm{nmol} / \mathrm{min} / \mathrm{mL})$ & $28.1 \pm 2.2$ & $14.4 \pm 2.3$ & 13.6 & $<0.001^{*}$ \\
\hline $\mathrm{XO}(\mathrm{U} / \mathrm{g})$ & $38.1 \pm 6.2$ & $12.2 \pm 2.1$ & 12.5 & $<0.001^{*}$ \\
\hline
\end{tabular}

$t$ : Student's $t$-test. Results are presented as mean \pm SD. Means within the same column in each category (mean \pm SE). MPO: myloperoxidase; XO: Xanthine oxidase. * represent P-value, where $p$-value $<0.001$ was considered highly significant.

\subsubsection{CRP Levels in the Serum}

The CRP levels in the serum were detected after the induction of diabetes with STZ in deep wounds group (Figure 4). They significantly increased in the control group compared with the animals treated with the extract of Combretum molle.

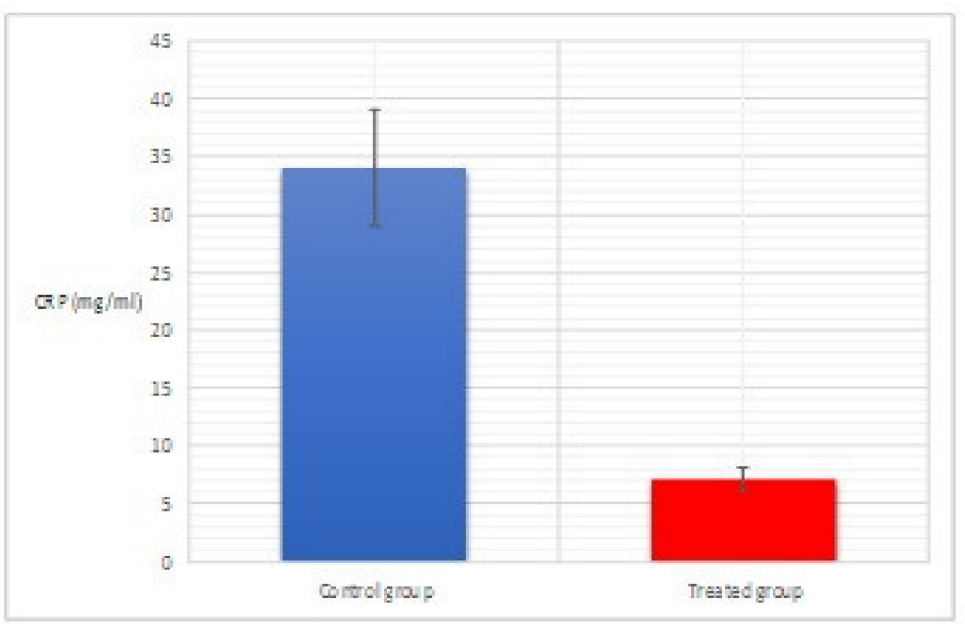

Figure 4. CRP levels in the serum were detected in diabetic untreated and treated group with C. molle.

\subsubsection{SDH, ROS, Cytochrome-C, ATP, and MMP}

The viable cells detected using ROS are presented in Figure 5. The ROS were significantly increased in the untreated diabetic control animals with deep wounds and decreased significantly in the diabetic deep wound group treated with the extract of Combretum 
molle. The viable cell numbers detected using $\mathrm{SDH} \%$ is presented in Figure 6. The SDH percentages were $80.38 \%$ and $61.76 \%$ in the untreated diabetic control animals with deep wounds and decreased significantly to $25.36 \%$ and $12.35 \%$ in the diabetic deep wound group that was treated with the extract of Combretum mole; similar results were seen for swelling mitochondria level, cytochrome-C, ATP and MMP (Mitochondrial membrane potential activity) levels as shown in Figures 7-10.

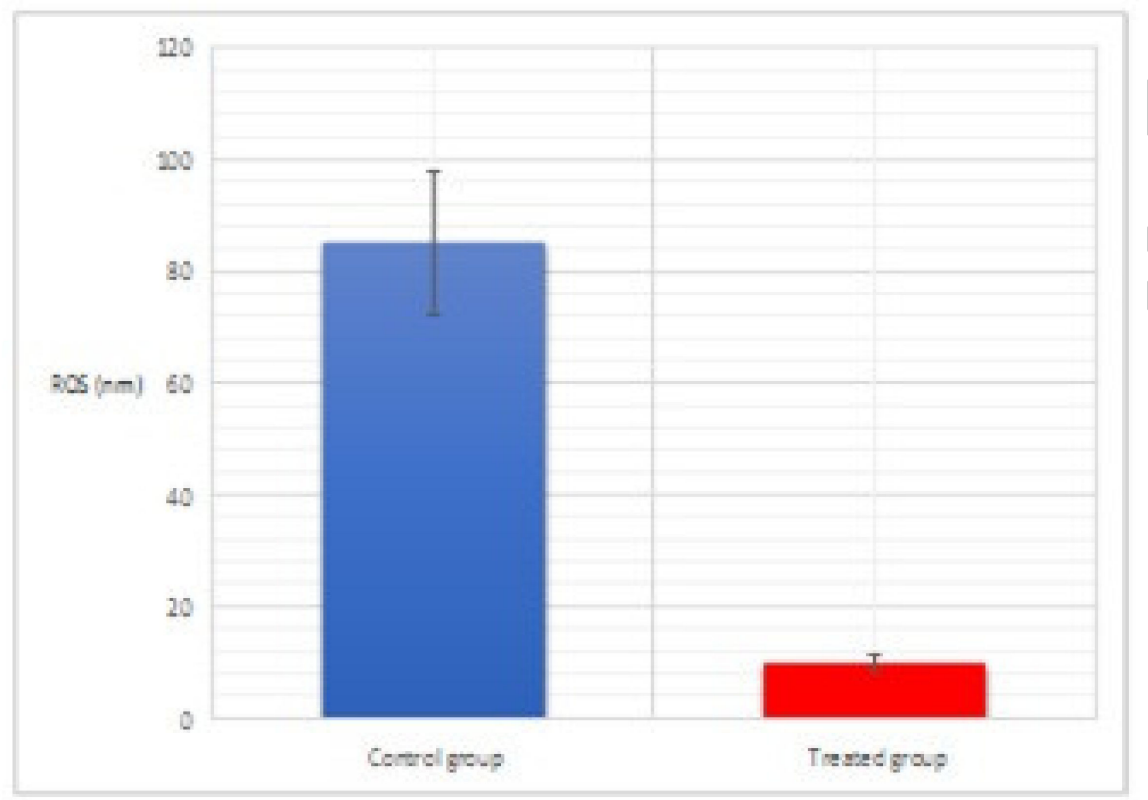

Figure 5. ROS levels in the serum were detected in diabetic untreated and treated group with C. molle.

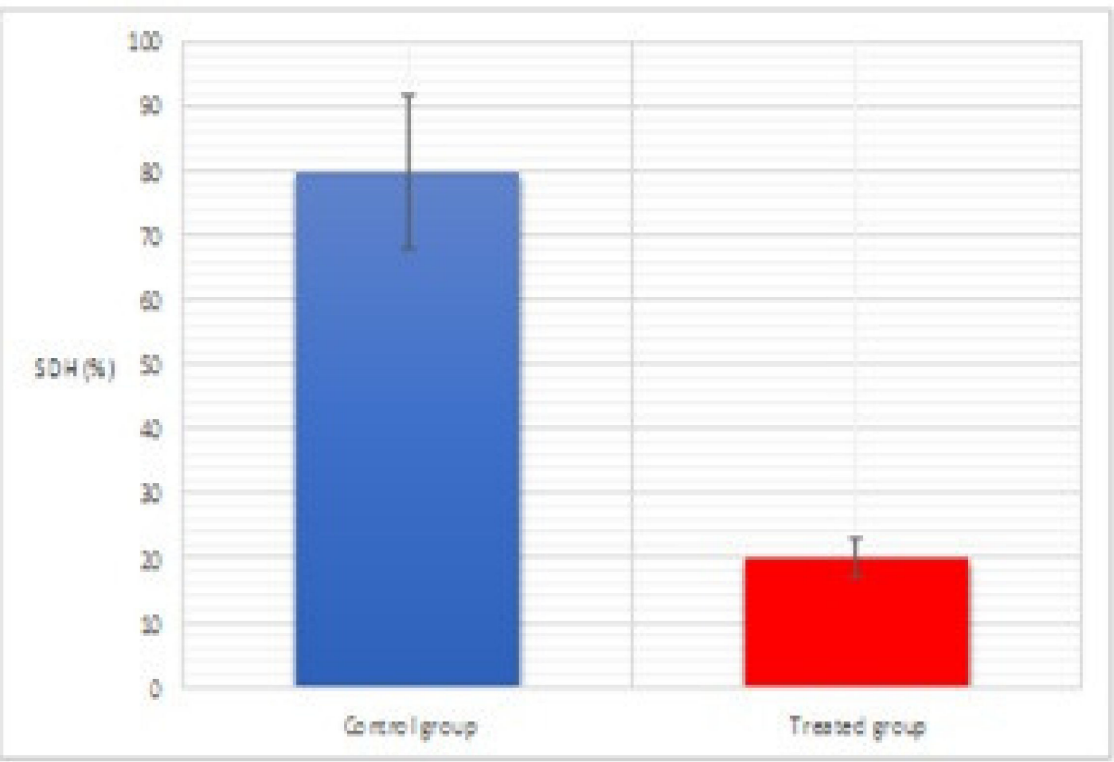

Figure 6. $\mathrm{SDH} \%$ in the serum were detected in diabetic untreated and treated group with C. molle. 

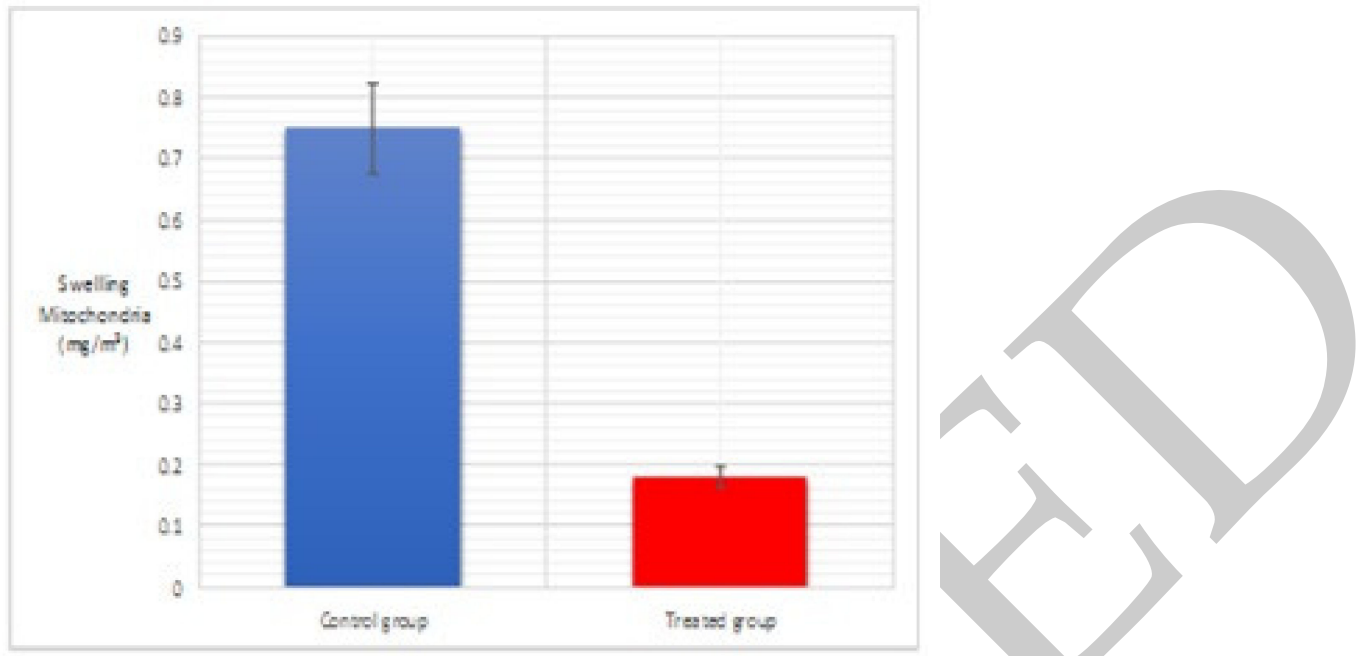

Figure 7. Swelling mitochondria in the serum were detected in diabetic untreated and treated group with C. molle.

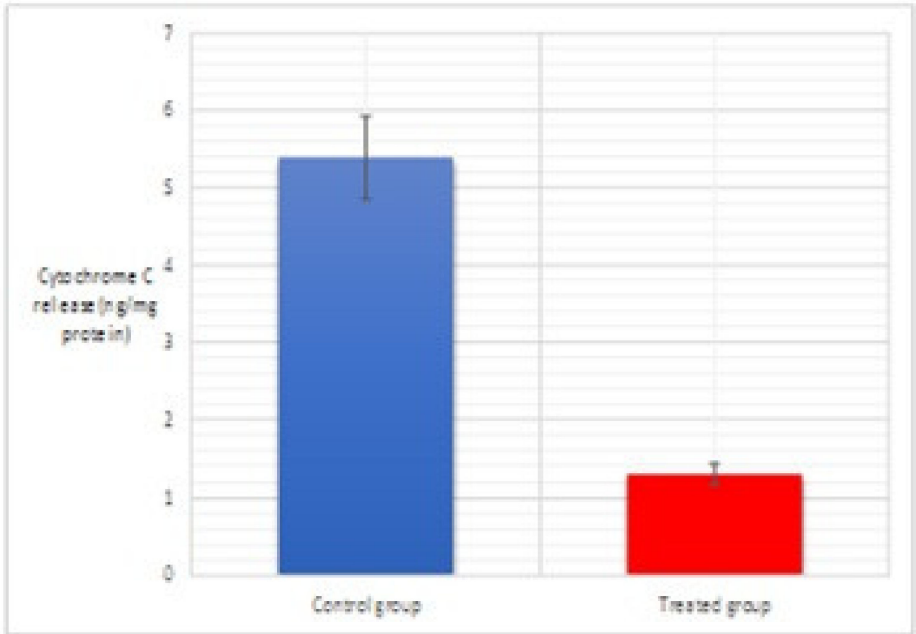

Figure 8. Cytochrome-C in the serum were detected in diabetic untreated and treated group with C. molle.

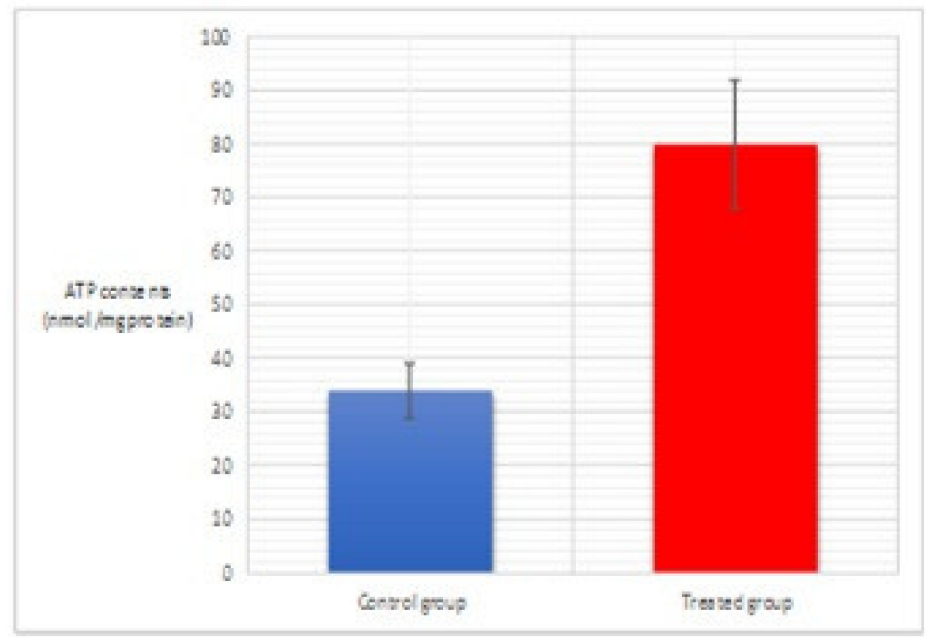

Figure 9. ATP in the serum were detected in diabetic untreated and treated group with C. molle. 


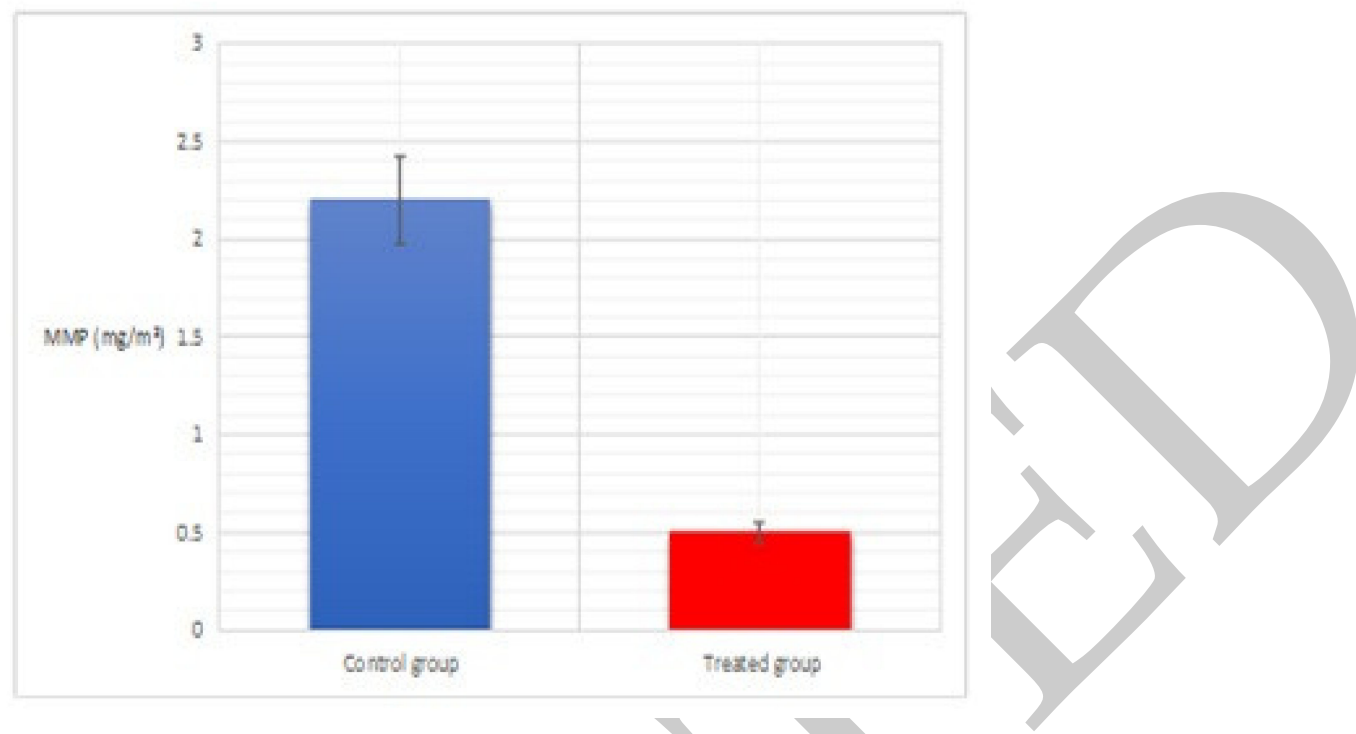

Figure 10. MMP in the serum were detected in diabetic untreated and treated group with C. molle.

\subsubsection{Mitochondrial Membrane Potential}

ROS accumulation is considered to be a hallmark of oxidative cellular death. When DCFH-DA was used as a ROS-sensitive fluorescence indicator, the accumulation of ROS in the skin tissues was markedly elevated in the untreated diabetic deep wound group (A) $(50.0 \mu \mathrm{m})$. In contrast, the fluorescent detection of the mitochondrial membrane potential showed high improvements in the dermal tissues in the diabetic deep wound group that was treated with the extract of Combretum molle (B) $(50.0 \mu \mathrm{m})$ (Figure 11).
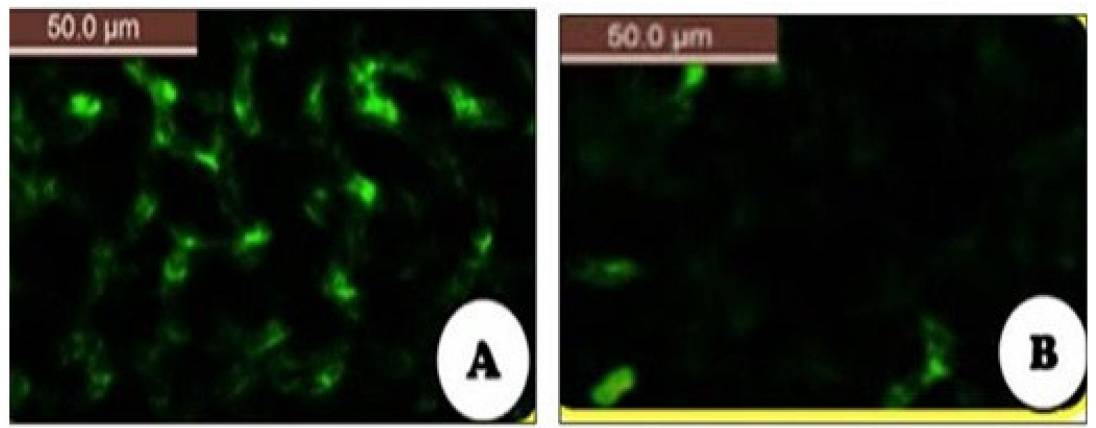

Figure 11. Mitochondrial membrane potential of the two groups: (A) diabetic group with a deep wound each (control group) and (B) diabetic group with a deep wound each that was treated with the C. molle extract.

\subsubsection{Gene Expression Levels in the Dermal Tissues of the Two Groups}

The antioxidant enzyme expression levels of the mouse CAT (mCAT) in rat skin are shown in Figure 12, which was analyzed by using semiquantitative PCR. The relative levels of expression of mCAT were significantly decreased in the diabetic untreated group compared with those in the diabetic group treated with the extract of Combretum molle.

\subsubsection{Histological Examination}

Figure 13 depicts photomicrographs of skin sections showing (A) the control diabetic deep wound non-treated group with epidermal ulceration $\left.{ }^{* *}\right)$ with infiltration of the dermis by dense aggregates of esinophils (orange head arrow) and (B-D) the treated diabetic deep wound group showing improvement in the dermal layers, which is represented by the partial restoration of the epidermis layer and the formation of its keratinized layers in first and third $\left({ }^{*}\right)$ and black arrow, respectively) weeks of treatment, with almost complete 
restoration of the epidermal layer after the fourth week of treatment (red arrow). All the sections were taken using the same resolution (H \& EX100) to visualize the whole field.

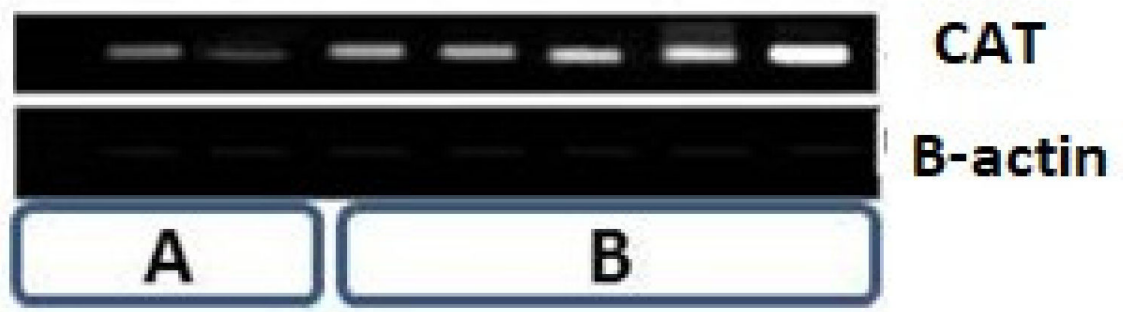

Figure 12. Gene expression of $\mathrm{mCAT}$ and $\mathrm{m} \beta$-actin in the dermal tissues of the diabetic control group and the group treated with the C. molle extract: (A) diabetic control group with a deep each wound and (B) diabetic group with a deep wound each and treatment with C. molle.
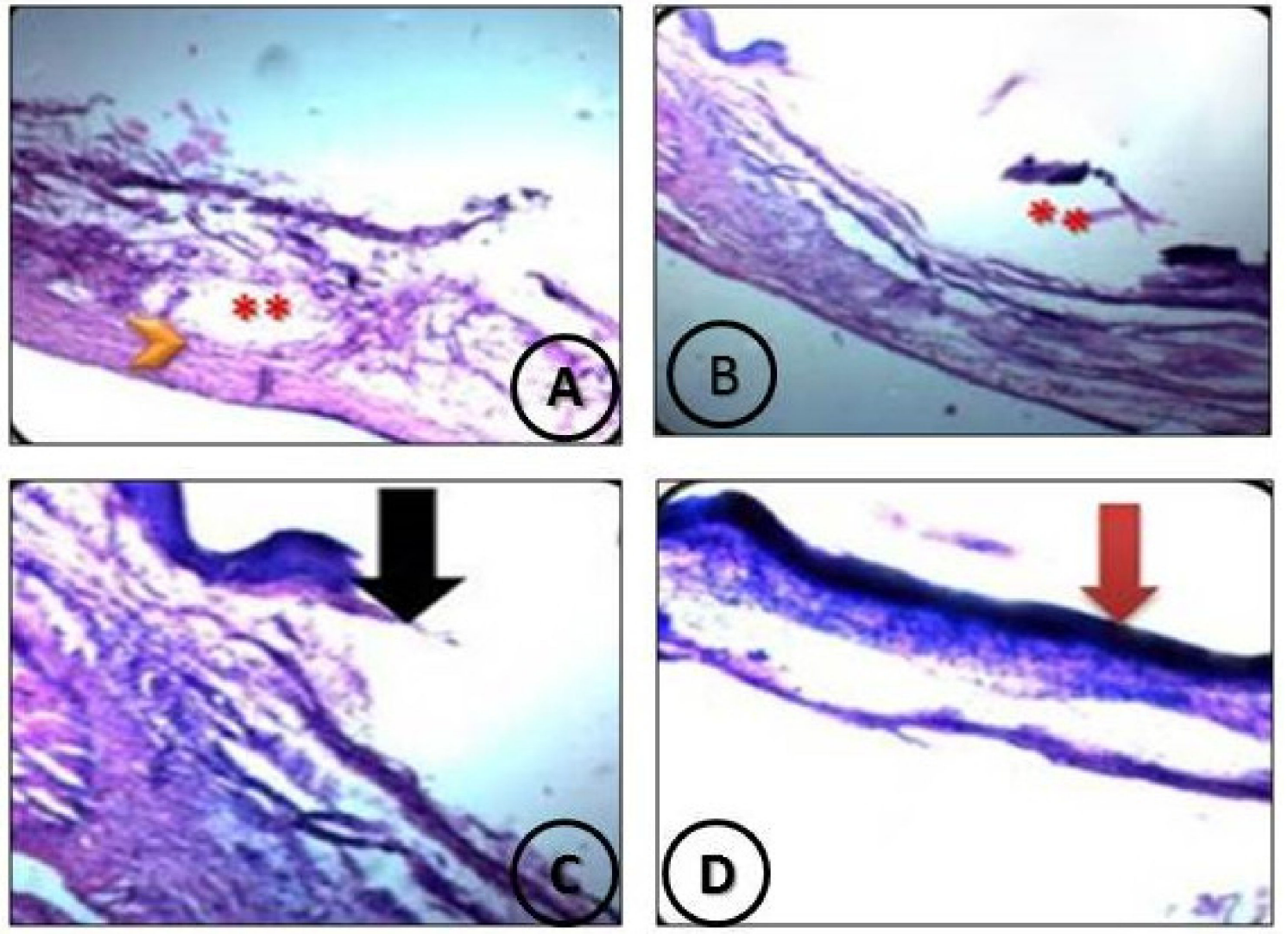

Figure 13. Histological sections of the diabetic untreated group and the diabetic group treated with the C. molle extract. (A) Control diabetic deep wound non-treated group with epidermal ulceration ${ }^{* *}$ ) with infiltration of the dermis by dense aggregates of esinophils (orange head arrow). (B-D) Treated diabetic deep wound group showing improvement in the dermal layers, which is represented by the partial restoration of the epidermis layer and the formation of its keratinized layers in first and third $\left(^{* *}\right)$ and black arrow, respectively) weeks of treatment, with almost complete restoration of the epidermal layer after the fourth week of treatment (red arrow) (H \& EX100).

\subsubsection{TEM Examination}

Figure 14 shows electron micrographs of dermal tissues showing the untreated diabetic deep wound group showing ruptured dermal layers (red arrow), with the appearance of red blood corpuscles (RB), along with the appearance of the restoration of almost all 
dermal components in the diabetic deep wound group treated with the novel extract (scale bar $=5 \mu \mathrm{m})$.
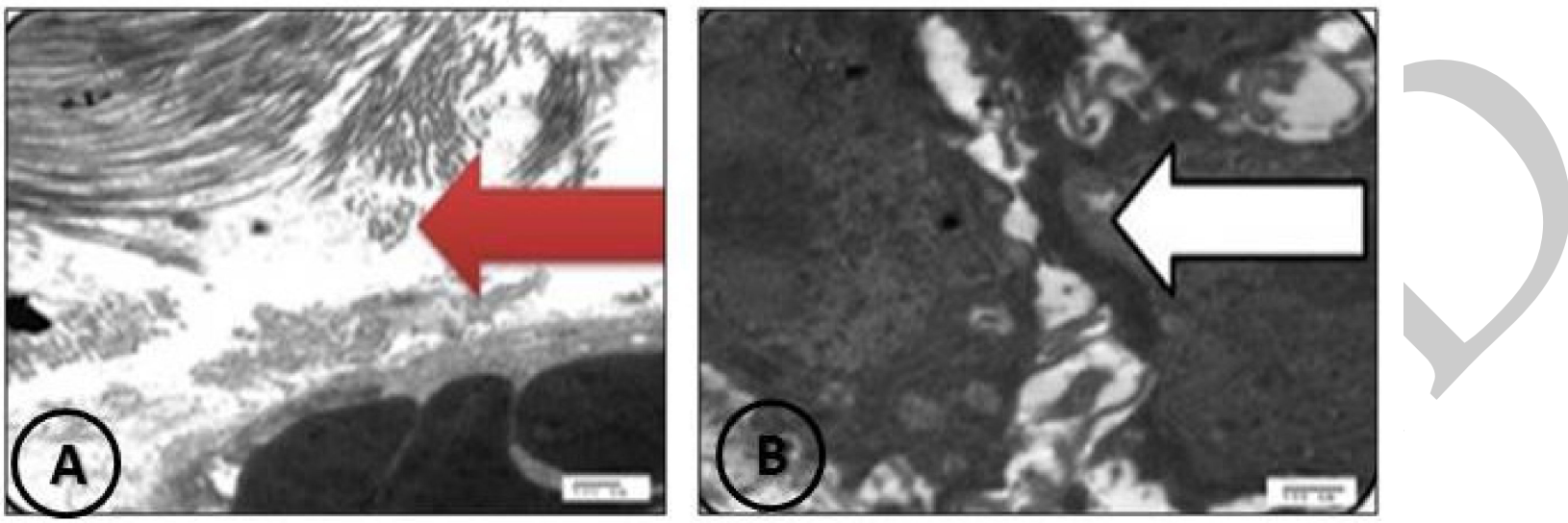

Figure 14. Ultrastructure sections of the untreated diabetic group and the diabetic group treated with the C. molle extract. (A) Untreated diabetic deep wound group showing ruptured dermal layers (red arrow). (B) Treated diabetic deep wound group with $C$. molle extract showed restoration of almost all dermal components.

\section{Discussion}

The use of natural plants in wound healing treatment has been developed since ancient times, which is due to the fact that treatments with plant extracts are easily accessible and mostly safe and there is global interest in using natural products against skin pathology [38].

The wounds of diabetic patients or even burned patients are very difficult to heal, which could lead to serious consequences, such as limb amputation or even death. These experiments aimed to assess the effect of an extract of Combretum molle, which could accelerate the process of wound healing, especially in diabetics.

It is a major clinical issue to manage, control, and treat the pathophysiology of the foot ulcers that emerge in diabetic foot. The extract of Combretum molle could be an ideal dressing material as all the chemicals present in the Combretum molle extract could provide regeneration of the detached skin, adequate moisture, stimulation of the growth factors, regulation of the endogenous protease, antimicrobial activity, permeability for gaseous exchange, and an antioxidant effect. As such, this promotes the infiltration and regeneration of the epithelial tissues and offers great antioxidant activities against free radicals due to the presence of potent antioxidants, such as flavonoids and phenolic compounds.

One of the important chemicals found in this plant is lignin. Lignin is one of the most abundant plant-based biopolymers in the world, after cellulose, and is, therefore, a sustainable raw material. Because of its physical strength and durability, lignin is often found as a structural component of the cell walls of plants, allowing them to grow tall, as well as protecting them from microorganisms. Additionally, lignin also comprises one of the main structural components of the vascular system of many plants, where its hydrophobic nature aids in the transport of water. Chemically, lignin demonstrates a random dendritic network that is composed of phenylpropane groups that create a complex three-dimensional structure with many functionalities and covalent linkages [39]. These findings are in agreement with the current findings, which reveal the great healing effect of the Combretum molle extract regarding healing deep wounds and mitigating the effects on the skin due to the healing properties of lignin, which is a component of the Combretum molle extract.

In this study, we established a rat model of diabetic foot with deep wounds and deep burn wounds, which recreated and mimicked the characteristics of foot ulcers in humans and revealed the therapeutic efficacy of this treatment.

Additionally, we investigated the effects of the Combretum molle extract. As mentioned previously, the differences between the ulcer healing process in rodents' thighs and in feet 
were reconfirmed in the current study. To resolve the problem, we compared the processes in the skin of the foot. As expected, wound contraction contributed to the healing in the foot after using the Combretum molle extract, and our results confirmed the quick healing of the wounds in the foot thanks to the action of Combretum molle extract.

One of the important compounds of Combretum molle, as indicated in UHPLC analysis, was the presence of gallic acid, as confirmed previously by [40], who stated that gallic acid plays an important role in wound healing and presents as a potent antioxidant as it directly upregulates the expression of the antioxidant genes and stimulates skin regeneration and more keratinocytes and fibroplasts; this finding strongly confirmed the obtained results in the current study and the great ability of Combretum molle in wound healing, especially in diabetics, as the used extract can overcome the problem of poor circulation in diabetics.

Technological achievements of the chemical, physical, and morphological nature of the dressings and wound healing materials allow for their ability to be effective in treating chronic hard-to-heal diabetic foot ulcers. However, there are some side effects, such as no assurance of restoration of a healthy appearance of the normal architecture of the skin; this is what drove us to investigate the healing activity of Combretum molle extract to both enhance the healing of wounds with the promotion of regeneration and restoring the healthy appearance of the skin, which is an important aspect of healing.

A specific approach to wound filling can be considered mainly after extensive study on the severity and the cellular responses to strategically manage the challenging etiology of the foot ulcers from either diabetes or burning. Inclusion of the Combretum molle treatment strategy with the dressing material for the accuracy of the healing of the wound and quick delivery of the drug is a real challenge to be addressed. However, the Combretum molle extract provides great promise regarding the healing of deep wounds and ulcers, as shown clearly in the histological and ultrastructural sections.

In this study, we established a rat model with diabetic foot with deep wounds, which recreated and mimicked the characteristics of foot ulcers in humans and revealed the therapeutic efficacy of the C. molle extract.

We revealed an acceleration of the healing in the diabetic rats given the $C$. molle extract. As revealed in the histological findings, regeneration of the epithelium layer appeared to be involved in the healing process of this foot ulcer model, as previously reported by [41].

According to the chemical analysis, C. molle was rich in gallic acid, where gallic acid has an important role in wound healing, as previously reported by Yang et al. [22]. Skin, which is the outermost layer of the human body and is constantly exposed to environmental stressors, is susceptible to severe wounding and injury, and diabetic patients often suffer from chronic, impaired wound healing, which facilitates bacterial infections and necessitate high levels of care. Gallic acid has a great effect on wound healing in normal and hyperglucidic conditions that mimic diabetes. Therefore, these findings are in agreement with the chemical characterization and excellent abilities of $C$. molle regarding wound healing.

The detection of CAT levels in the treated diabetic group and the burn wound group treated with the Combretum molle extract was due to the correlation between CAT levels and skin damage, as catalase is the main enzyme responsible for degrading $\mathrm{H}_{2} \mathrm{O}_{2}$, and low basal levels of catalase activity are associated with the light phototype in in vitro models. Previous studies investigated the possible correlation between its activity and melanogenesis in primary cultures of human melanocytes and CAT, where they showed that catalase-specific mRNA, proteins, and enzymatic activity were all directly correlated with the total cellular melanin content and tissue damage, which is in agreement with the lower expression of CAT levels in the untreated diabetic groups [42] and the high expression of CAT in the diabetic and burned groups that were treated with the Combretum molle extract.

The current findings are consistent with that of Mensah et al. [8], who demonstrated that Combretum molle and Xylopia aethiopica (fruit) indicated a strong antioxidant synergism, in addition to antifungal synergism effects; these results confirm our obtained findings. 
Based on its historical ethnomedicinal use and the strength of this experimental evidence, Combretum molle may be regarded not only as a suitable botanical phytochemical with which to initiate and sustain healthy wound healing but also to elucidate some of the primary molecular events that occur mechanistically during healthy wound healing, which is a point of major significance for diabetics.

\section{Conclusions}

The current results show that using Combretum molle extract has great potential for wound healing and ulcer repair in diabetic foot models and deep wound ulcers. This is exemplified in the extract's promising capacity for skin regeneration and the restoration of the healthy appearance of the skin in a suitable period by fighting against damaging effects and promoting antioxidant enzyme regeneration, as shown in the live images of the wounds at all stages of the treatment period and the great healing abilities of the Combretum molle extract.

Author Contributions: Conceptualization, R.Z.H. and S.E.A.-M.; Data curation, R.Z.H. and T.A.-T.; Formal analysis, R.Z.H.; Funding acquisition, S.E.A.-M.; Investigation, R.Z.H., T.A.-T. and S.E.A.-M.; Methodology, S.E.A.-M.; Resources, R.Z.H.; Validation, T.A.-T., R.Z.H. and S.E.A.-M.; Visualization, R.Z.H. and T.A.-T. All authors have read and agreed to the published version of the manuscript.

Funding: Taif University Researcher supporting project number (TURSP-2020/21), Taif University, Taif, Saudi Arabia.

Institutional Review Board Statement: This study's experimental protocol was approved by Deanship of Scientific Research's "Animal Ethical Committee" of Taif University under approval number 42-0044 following the guidelines of animal use and care. All the experimental procedures involving animals were conducted in accordance with the institutional animal care guidelines of the ethical committee of Taif University.

Informed Consent Statement: Not applicable.

Data Availability Statement: The data presented in this study are available upon request corresponding author.

Acknowledgments: Taif University Researcher supporting project No. (TURSP-2020/21), Taif University, Taif, Saudi Arabia.

Conflicts of Interest: The authors declare no conflict of interest.

\section{References}

1. Merkin, A.; Mesele, B.; Tsige, K. Effect of Combretum molle (Combretaceae) seed extract on hematological and biochemical parameters. J. Med. Plants Res. 2018, 12, 55-63. [CrossRef]

2. Eloff, J.N.; Katerere, D.R.; Mcgaw, L.J. The biological activity and chemistry of the southern African Combretaceae. J. Ethnopharmacol. 2008, 119, 686-699. [CrossRef]

3. Fyhrquist, P.; Mwasumbi, L.; Haeggstro, C.A.; Vuorela, H.; Hiltunen, R.; Vuorela, P. Ethnobotanical and antimicrobial investigation on some species of Terminalia and Combretum (Combretaceae) growing in Tanzania. J. Ethnopharmacol. 2012, 79, 169-177. [CrossRef]

4. Sahlu, T. Antibacterial Activities and Preliminary Phytochemical Investigation of Four Selected Medicinal Plants. Master's Thesis, Addis Ababa University, Addis Ababa, Ethiopia, 2013.

5. Amare, T.; Tadesse, E. In vitro Antibacterial Effect of Combretum molle and Fr1 against Staphylococcus aureus and E. coli Isolated from Bovine Mastitis. World J. Biol. Med. Sci. 2016, 3, 115-131.

6. Ademola, O.; Eloff, N. In vitro anthelmintic activity of Combretum molle ex (Combretaceae) against Haemonchus contortusova and larvae. Vet. Parasitol. 2010, 169, 198-203. [CrossRef] [PubMed]

7. Sanon, S.; Gansane, A.; Ouattara, L.P.; Traore, A.; Ouedraogo, I.N.; Tiono, A.; Taramelli, D.; Basilico, N.; Sirima, S.B. In vitro antiplasmodial and cytotoxic properties of some medicinal plants from western Burkina Faso. Afr. J. Lab Med. $2013,2,81$. [CrossRef]

8. John, K.M.; Mustapha, A.; Yakubu, J. Aqueous Co-extract Mixture of Combretum molle (stembark) and Xylopia aethiopica (fruit) show Phytochemical Synergy in its Anti-fungal and Antioxidant Bioactivities. Adv. Complement Alt. Med. 2020, 6, 560-575.

9. Trikkalinou, A.; Papazafiropoulou, A.K.; Melidonis, A. Type 2 diabetes and quality of life. World J. Diabetes 2017, 8, 120. [CrossRef] [PubMed] 
10. Sun, M.; Qianjin, X.; Xiaqiang, C.; Zenghui, L.; Ying, W.; Xu, D.; Yan, X. Preparation and characterization of epigallocatechin gallate, ascorbic acid, gelatin, chitosan nanoparticles and their beneficial effect on wound healing of diabetic mice. Int. J. Biol. Macromol. 2020, 148, 777-784. [CrossRef]

11. Paul, E.J.; Padmapriya, B. A pragmatic review on the property, role and significance of polymers in treating diabetic foot ulcer. Mater. Today Proc. 2020, 23, 91-99. [CrossRef]

12. Fard, A.S.; Esmaelzadeh, M.; Larijani, B. Assessment and treatment of diabetic foot ulcer. Int. J. Clin. Pract. 2007, 61, 1931-1938. [CrossRef]

13. ADM. American Diabetes Association. Standards of medical care in diabetes-2014. Diabetes Care 2014, 37, 14-80. [CrossRef]

14. Soliman, A.M.; Teoh, S.L.; Norzana, A.; Ghafar, S.D. Virgin coconut oil and diabetic wound healing: Histopathological and biochemical analysis. Eur. J. Anat. 2018, 22, 135-144.

15. Shahbazian, H.; Yazdanpanah, L.; Latifi, S.M. Risk assessment of patients with diabetes for foot ul-cers according to risk classification consensus of Inter-national Working Group on Diabetic Foot (IWGDF). Pak. J. Med. Sci. 2013, 29, 730-734. [CrossRef]

16. Gansane, A.; Sanon, S.; Ouattara, L.P.; Traore, A.; Hutter, S.; Ollivier, E.; Azas, N.; Traore, A.S.; Guissou, I.P.; Sirima, S.B. Antiplasmodial activity and toxicity of crude extracts from alternatives parts of plants widely used for the treatment of malaria in Burkina Faso: Contribution for their preservation. Parasitol. Res. 2010, 106, 335-340. [CrossRef]

17. Miaffo, D.; Wansi, S.L.; Mbiantcha, M.; Poualeu, S.L.K.; Guessom, O.K. Toxicological Evaluation of Aqueous and Acetone Extracts of Combretum molle Twigs in Wistar Rats. Electron. J. Biol. 2015, 11, 33-45.

18. Snyder, R.J.; Hanft, J.R. Diabetic foot ulcers-Effects on QOL, costs, and mortality and the role of standard wound care and advanced-care therapies. Ostomy Wound Manag. 2009, 55, 28-38.

19. Nasab, M.E.; Nasrin, T.; Partow, M.S.; Alireza, P. In vitro antioxidant activity and in vivo wound-healing effect of lecithin liposomes: A comparative study. J. Comp. Eff. Res. 2019, 8, 633-643. [CrossRef]

20. Pazyar, N.; Yaghoobi, R.; Rafiee, E.; Mehrabian, A.; Feily, A. Skin wound healing and phytomedicine: A review. Skin Pharmacol. Physiol. 2014, 27, 303-310. [CrossRef] [PubMed]

21. Meyer, T.N.; Da Silva, A.L. A standard burn model using rats. Acta Cir Bras 1999, 14. [CrossRef]

22. Yang, D.J.; Moh, S.H.; Son, D.H.; You, S.; Kinyua, A.W.; Ko, C.M.; Song, M.; Yeo, J.; Choi, Y.H.; Kim, K.W. Gallic Acid Promotes Wound Healing in Normal and Hyperglucidic Conditions. Molecules 2016, 21, 899. [CrossRef]

23. El-Megharbel, S.M.; Hamza, R.Z.; Gobouri, A.A.; Refat, M.S. Synthesis of new antidiabetic agent by complexity between vanadyl (II) sulfate and vitamin B1: Structural, characterization, anti-DNA damage, structural alterations and antioxidative damage studies. Appl. Organomet. Chem. 2019, 33, e4892. [CrossRef]

24. Litwack, G.; Bothwell, J.W.; Williams, J.N.; Elvehjem, C.A. A colorimetric assay for xanthine oxidase in rat liver homogenates. J. Biol. Chem. 1953, 200, 303. [CrossRef]

25. Sedlak, J.; Lindsay, R.H. Estimation of total, protein-bound, and nonprotein sulfhydryl groups in tissue with Ellman's reagent. J. Anal. Biochem. 1968, 25, 192. [CrossRef]

26. Ohkawa, H.; Ohishi, N.; Yagi, K. Assay for lipid peroxides in animal tissues by thiobarbituric acid reaction. Anal. Biochem. 1979, 95, 351. [CrossRef]

27. Beers, J.R.; Sizer, I.W. A spectrophotometric method for measuring the breakdown of hydrogen peroxide by catalase. J. Biol. Chem. 1952, 195, 133. [CrossRef]

28. Couri, D.; Abdel-Rahman, M.S. Effect of chlorine dioxide and metabolites on glutathione dependent system in rat, mouse and chicken blood. J. Environ. Pathol. Toxicol. 1979, 3, 451-460. [PubMed]

29. Goldberg, D.M.; Spooner, R.J. Methods of Enzymatic Analysis, 3rd ed.; Bergmeyen, H.V., Ed.; Elsevier Inc.: Amsterdam, The Netherlands, 1983; Volume 3, pp. 258-265.

30. Wener, M.H.; Daum, P.R.; McQuillin, G.M. The influence of age, sex, and race on the upper reference limit of serum C-reactive protein concentration. J. Rheumatol. 2000, 27, 2351-2359.

31. Suzuki, K.; Ota, H.; Sasagawa, S.; Sakatani, T.; Fujikura, T. Assay method for myeloperoxidase in human polymorphonuclear leukocytes. Anal Biochem. 1983, 132, 345-352. [CrossRef]

32. Zhao, Y.; Ye, L.; Liu, H.; Xia, Q.; Zhang, Y.; Yang, X.; Wang, K. Vanadium compounds induced mitochondria permeability transition pore (PTP) opening related to oxidative stress. J. Inorg. Biochem. 2010, 104, 371-378. [CrossRef]

33. Ayoubi, M.; Naserzadeh, P.; Hashemi, M.T.; Rostami, M.R.; Tamjid, E.; Tavakoli, M.M.; Simchi, A. Biochemical mechanisms of dose-dependent cytotoxicity and ROS-mediated apoptosis induced by lead sulfide/graphene oxide quantum dots for potential bioimaging applications. Sci. Rep. 2017, 7, 12896. [CrossRef]

34. Naserzadeh, P.; Ansari, E.F.; Kaviani, M.; Ashtari, K.; Kheirbakhsh, R.; Salimi, A.; Pourahmad, J. Single-walled carbon nanotube, multiwalled carbon nanotube, and $\mathrm{Fe}_{2} \mathrm{O}_{3}$ nanoparticles induced mitochondria-mediated apoptosis in melanoma cells. Cutan. Ocul. Toxicol. 2018, 37, 157-166. [CrossRef] [PubMed]

35. Tafreshi, N.; Hosseinkhani, S.; Sadeghizadeh, M.; Sadeghi, M.; Ranjbar, B.; Naderi-Manesh, H. The influence of insertion of a critical residue (Arg356) in structure and bioluminescence spectra of firefly luciferase. J. Biol. Chem. 2007, 282, 8641-8647. [CrossRef]

36. Hayat, M.A. Basic Techniques for Transmission Electron Microscopy, 1st ed.; Hayat, M.A., Ed.; Macmillan Press: New York, NY, USA, 1986; ISBN 9780123339263.

37. Petrie, A.; Sabin, C. Medical Statistics at a Glance, 3rd ed.; Wiley-Blackwell: Hoboken, NJ, USA, 2009 ; Volume 23. 
38. Hailing, L.; Hoyong, C. Self-Healing Properties of Lignin-Containing Nanocomposite: Synthesis of Lignin-graft-poly (5acetylaminopentyl acrylate) via RAFT and Click Chemistry. Macromolecules 2016, 49, 7246-7256.

39. Fukui, M.; Choi, H.J.; Zhu, B.T. Mechanism for the protective effect of resveratrol against oxidative stress-induced neuronal death. Free. Radic. Biol. Med. 2010, 49, 800-813. [CrossRef] [PubMed]

40. Maresca, V.; Flori, E.; Briganti, S.; Mastrofrancesco, A.; Fabbri, C.; Mileo, A.M.; Paggi, M.G.; Picardo, M. Correlation between melanogenic and catalase activity in in vitro human melanocytes: A synergic strategy against oxidative stress. Pigment. Cell Melanoma Res. 2008, 21, 200-205. [CrossRef] [PubMed]

41. Fyhrquist, P.; Laakso, I.; Garcia Marco, S.; Julkunen-Tiitto, R.; Hiltunen, R. Antimycobacterial activity of ellagitannin and ellagic acid derivative rich crude extracts and fractions of five selected species of Terminalia used for treatment of infectious diseases in African traditional medicine. S. Afr. J. Bot. 2014, 90, 1-16. [CrossRef]

42. Refat, M.S.; Hamza, R.Z.; Adam, A.A.; Saad, H.A.; Gobouri, A.A.; Al-Harbi, F.S.; Al-Salmi, F.A.; Altalhi, T.; El-Megharbel, S.M. Quercetin/Zinc complex and stem cells: A new drug therapy to ameliorate glycometabolic control and pulmonary dysfunction in diabetes mellitus: Structural characterization and genetic studies. PLoS ONE. 2021, 16, e0246265. [CrossRef] [PubMed] 